\title{
Full Paper \\ Chemotherapy for early-stage breast cancer: a brief history
}

\author{
M Verrill*,I \\ 'Northern Centre for Cancer Care, Freeman Hospital, High Heaton, Newcastle upon Tyne NE7 7DN, UK
}

The advent of chemotherapy for early-stage breast cancer has ushered in a new age of management for the condition. This article charts the evolution of chemotherapy for breast cancer, and highlights the current need for carefully planned, fully implemented local protocols to support the delivery of modern regimens.

British Journal of Cancer (2009) I 0 I, S2 - S5. doi:I0.1038/sj.bjc.6605268 www.bjcancer.com

(c) 2009 Cancer Research UK

Keywords: chemotherapy; adjuvant; anthracycline; docetaxel; neutropenia

Breast cancer has been recognised since at least $1600 \mathrm{BC}$, when an ancient Egyptian medical text (Smith, 2006) described eight cases of a tumour or ulcer of the breast that were treated by cauterisation. There followed many historical reports of the disease, all concluding that there was no cure.

In the seventeenth century, an understanding of the lymphatic circulation enabled the link to be made between the breast and the axillary lymph nodes, and led to the first lymph node surgery in women with breast cancer (Sakorafas, 2008). Radical surgery for breast cancer reached its zenith in the nineteenth century, at the hands of the US surgeon William Halsted, who removed not only the affected breast, but also the contralateral breast, all associated lymph nodes, and the underlying pectoral muscles (Halsted, 1907). This morbid and mutilating procedure was deemed necessary to prevent recurrence, but did little to change the natural history of the disease.

In the twenty-first century, breast cancer is the most common cancer in the United Kingdom, with in excess of 45000 women and around 300 men diagnosed in 2005 (Cancer Research UK, 2009). However, the past half century has seen the emergence and evolution of new therapeutic approaches for breast cancer, including chemotherapy, radiotherapy and conservative surgery (Figure 1).

\section{THE BIRTH OF CHEMOTHERAPY}

After the Second World War, the observation by Goodman and Gilman that nitrogen mustards had the potential for anticancer effects (Gilman, 1946), and parallel work on antifolates by Farber et al (1948), led to the first successful drug treatments for cancer (Goodman et al, 1984). Subsequently, observations of uracil uptake by normal rat mucosa and tumours led to the development of 5-fluorouracil (Heidelberger et al, 1957), and then cyclophosphamide + methotrexate +5 -fluorouracil $(\mathrm{CMF})$ - the first effective chemotherapy regimen for breast cancer (Bonadonna et al, 1976).

CMF was tested in the 1970s by Bonadonna et al (1976) and the Milan group. Their demonstration that the risk of breast cancer recurrence after surgery could be reduced with the addition of

*Correspondence: Dr M Verrill; E-mail: Mark.Verrill@nuth.nhs.uk adjuvant chemotherapy paved the way for the development of surgical procedures less morbid than those pioneered by Halsted. Later, trials from the US National Surgical Adjuvant Breast and Bowel Project (NSABP) established that a combination of lumpectomy and radiotherapy was equivalent to mastectomy in terms of outcome (Fisher et al, 2002).

\section{NEW CHEMOTHERAPY AGENTS}

Although the Milan group was the first to describe the use of an anthracycline (doxorubicin) in metastatic breast cancer (Bonadonna et al, 1969), the first anthracycline-containing regimen to become a 'gold standard' was doxorubicin + cyclophosphamide (AC), investigated initially by the NSABP in the 1990s (Fisher et al, 1990). The rationale for including the anthracycline was to reduce the duration of treatment, the number of hospital visits and the need for antiemetic medication (classical CMF involves 2 weeks of oral cyclophosphamide for each cycle, and produces significant and long-lasting nausea) (Fisher et al, 1990). There was no efficacy advantage of AC over CMF, possibly because of the shorter duration of treatment and the elimination of both 5-fluorouracil and methotrexate from the combination, and over the ensuing 30 years, CMF and AC became references for the development of newer, more effective chemotherapy regimens on both sides of the Atlantic.

In early attempts to improve the efficacy of CMF, a number of investigators tested regimens where, in a 6-cycle regimen, an anthracycline (doxorubicin or epirubicin) was substituted for methotrexate to make either FAC (5-FU+doxorubicin + cyclophosphamide) or FEC (5-FU + epirubicin + cyclophosphamide). Various doses of the drugs have been tested using either the classic 4-weekly schedule or a shortened 3-weekly regimen, which has often been compared with 3-weekly all intravenous CMF. The FAC regimen is most commonly $5-\mathrm{FU} 500 \mathrm{mg} \mathrm{m}^{-2}$, doxorubicin $50 \mathrm{mg} \mathrm{m}^{-2}$ and cyclophosphamide $500 \mathrm{mg} \mathrm{m}^{-2}$, all 3 weekly (Martin et al, 2003). There are several FEC variations, leading to a degree of confusion when reference is made to the regimen, although there are several clearly defined schedules including 'French FEC' (French Adjuvant Study Group, 2001) and 'Canadian FEC' (Levine et al, 1998).

An alternative to the substitution of methotrexate is the addition of an anthracycline to CMF, in what is known as a block-sequential 


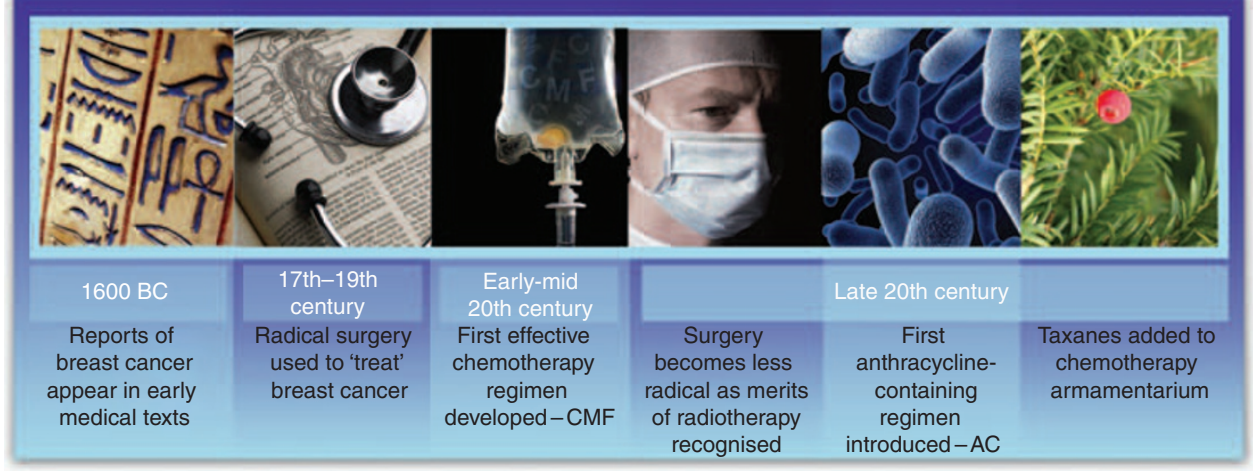

Figure I Chemotherapy evolution timeline.

design. In the National Epirubicin Adjuvant Trial, four cycles of epirubicin were followed by four cycles of CMF, resulting in significantly improved efficacy compared with six cycles of CMF alone (Poole et al, 2006).

In the 1970s, the development of the taxanes, the first new cytotoxic drugs for several decades with activity in metastatic breast cancer (Wani et al, 1971), was soon followed by the inclusion of paclitaxel or docetaxel in various adjuvant chemotherapy trial regimens (Henderson et al, 2003; Mamounas et al, 2005; Martin et al, 2005; Bear et al, 2006). In the United States, AC followed by paclitaxel in a block-sequential design was shown to be more effective than AC alone (Henderson et al, 2003). This regimen was subsequently 'accelerated' - given every 2 weeks rather than every 3 weeks - an adaptation made possible through the use of granulocyte colony-stimulating factor, which helped to prevent chemotherapy-associated neutropenia (Citron et al, 2003). The accelerated approach resulted in a further increment in antitumour activity (Citron et al, 2003).

Another major development was marked by the Breast Cancer International Research Group (BCIRG)-001 trial, in which the 5 -fluorouracil component of FAC was replaced by docetaxel, that is, the TAC regimen (Martin et al, 2005). The trial showed that TAC provided a significant improvement in efficacy compared with FAC. The French Adjuvant group modified FEC into a block-sequential regimen in which three cycles of FEC were followed by three cycles of docetaxel (FEC-T) (Roché et al, 2006). Since then, FEC-T has become a commonly used regimen following surgery for axillary lymph node-positive breast cancer in the United Kingdom.

\section{CURRENT REGIMENS FOR EARLY-STAGE BREAST CANCER}

There is currently no one gold standard regimen in early-stage breast cancer. The proliferation and diversity of trials, with varying interpretations of the standard of care, has led to endless conjecture on the best treatment, and much discussion of the route by which the 'latest' regimen to be tested has evolved. However, there is general agreement that CMF-like regimens are better than nothing, that anthracycline-containing regimens are better than CMF, and that the taxanes further add to the benefit of anthracyclines (Figure 2; Peto, 2007). The most robust evidence for this view comes from the Oxford overview of work by the Early Breast Cancer Trialists' Collaborative Group, which includes the details of more than 250000 women randomised into trials of polychemotherapy in early-stage breast cancer (Peto, 2007).

The latest guidelines on breast cancer management from the National Institute for Health and Clinical Excellence (NICE) emphasise the importance of chemotherapy for both early (NICE, 2009a) and advanced disease (NICE, 2009b). More specifically, for

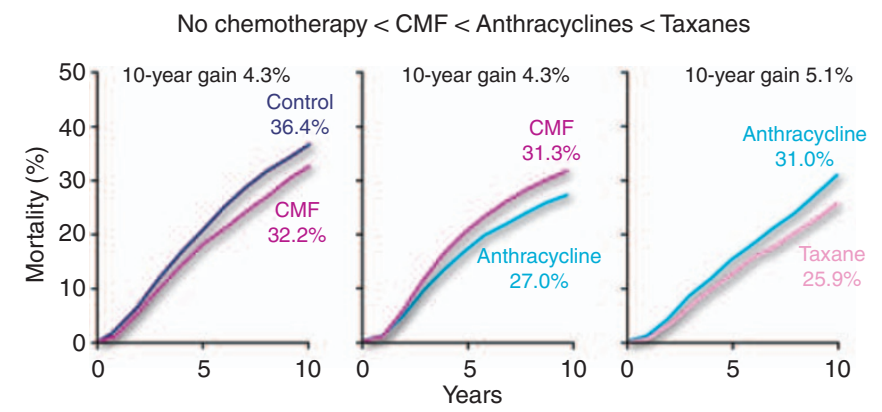

Figure 2 Stepwise improvements in efficacy of chemotherapy for earlystage breast cancer. Source: Preliminary data presented by R Peto at the 2007 San Antonio Breast Cancer Symposium on behalf of the Early Breast Cancer Trialists' Collaborative Group (EBCTCG).

lymph node-positive early or locally advanced breast cancer, NICE states that docetaxel, not paclitaxel, should be part of the chemotherapy regimen (NICE, 2009a). NICE also recommends docetaxel monotherapy in patients with advanced breast cancer in whom anthracyclines have failed or are contraindicated, and in combination chemotherapy (e.g., with trastuzumab) in patients whose tumours overexpress human epidermal growth factor receptor 2 (HER2) (NICE, 2009b). NICE only recommends the combination of gemcitabine and paclitaxel as an option for advanced breast cancer if docetaxel monotherapy or the combination of docetaxel and capecitabine would also be appropriate. In the first instance, however, the guideline states that, in the majority of cases, patients should start treatment with taxane monotherapy (preferably docetaxel) followed by second-line vinorelbine or capecitabine monotherapy and then by third-line capecitabine or vinorelbine monotherapy (NICE, 2009b).

\section{REGIMEN DELIVERY: PRACTICAL AND COST CONSIDERATIONS}

It is incumbent on the NHS to deliver treatments that are found to be effective in clinical trials, licensed by the European regulatory authorities and approved by NICE and the Scottish Medicines Consortium. Almost all NHS breast cancer units now have the facilities and expertise required to deliver complex chemotherapy regimens such as TAC. However, challenges remain, notably in service capacity, management and prevention of neutropenic complications, and the financial costs of chemotherapy.

Looking first at service capacity, it is clear that as thresholds for offering chemotherapy fall, the number of patients receiving treatment will increase. The introduction of trastuzumab as a routine adjuvant treatment for patients with breast cancers that 
overexpress HER2 has already stretched the system (NICE, 2009a), and there is concern that the growth in adjuvant therapies across cancer care as a whole will put increasing pressure on chemotherapy day units. Furthermore, there are now at least three studies, though the data are still preliminary, showing that the efficacy of standard breast cancer chemotherapy can be improved by the addition of a 6-monthly zoledronic acid infusion for 3 or 5 years (Coleman et al, 2006; Winter et al, 2008). Such an approach may save lives, but has the potential to more than double the number of intravenous treatments delivered to the population of patients with early-stage breast cancer, hence adding to the strain on resources.

The prevention and management of neutropenic events are covered in detail elsewhere in this supplement by Kelly and Wheatley, (2009); Cullen and Baijal, (2009) and Cameron, (2009). In summary, recent reports from the National Confidential Enquiry into Patient Outcome and Death (NCEPOD, 2008) and the National Chemotherapy Advisory Group (NCAG, 2009) have highlighted the need for clear, fully implemented local protocols for predicting, recognising and managing febrile neutropenia and neutropenic sepsis in patients receiving chemotherapy. In addition, there is international guidance on the use of G-CSF prophylaxis of neutropenia (Aapro et al, 2006; Smith et al, 2006).

Looking at the financial considerations, the drug acquisition cost for the UK-licensed TAC regimen is $£ 6554$ for six cycles, based on list prices, for a woman with a body surface area of $1.8 \mathrm{~m}^{2}$ (excluding VAT and assuming no drug wastage) (BNF, 2009). Six cycles of FAC for the same woman would cost $£ 1278$. Furthermore, in the BCIRG-001 trial, the febrile neutropenia rate for patients receiving TAC approached 25\% (Martin et al, 2005), well above the recommended threshold for primary prophylaxis with G-CSF (Aapro et al, 2006; Smith et al, 2006). If the cost of a standard $6 \mathrm{mg}$ dose of pegylated filgrastim is included, the drug acquisition cost increases to $£ 10839$.

Some cancer networks have adopted FEC-T as a standard for patients with axillary lymph node-positive breast cancer, despite the lack of a specific licence for the regimen in the United Kingdom. The practice may be based on trial data suggesting that the rate of febrile neutropenia associated with FEC-T is lower than the $20 \%$ threshold for primary G-CSF prophylaxis stipulated by the international guidelines (Aapro et al, 2006; Roché et al, 2006; Smith et al, 2006), allowing services to avoid the cost of G-CSF prophylaxis. However, data from two separate UK studies, presented at the National Cancer Research Institute's Cancer
Conference in 2008, do not support such an optimistic view of FEC-T's potential for reducing the risk of febrile neutropenia. Head et al (2008) reported a 25\% rate of neutropenic fever in 137 patients receiving FEC-T; all affected patients were given secondary prophylactic G-CSF and there were no further episodes of sepsis. The authors, from hospitals across south-east England recommend the use of primary prophylaxis in all patients receiving FEC-T. Ali et al (2008), from the Merseyside and Cheshire Cancer Network, reported a 27\% rate of febrile neutropenia in 123 FEC-T recipients, including six patients who had two episodes . Only $8 \%$ of patients had further sepsis following secondary prophylaxis with G-CSF, and the authors suggest that primary or secondary G-CSF should be considered for all patients using FEC-T (Head et al, 2008).

\section{CONCLUSION}

Although breast cancer remains a common malignancy, the outlook for women with early-stage disease has been transformed since the Halsted days when radical surgery was the only therapeutic option. Recent advances in chemotherapy for breast cancer have culminated, in England and Wales, in the latest NICE guidelines for the management of early and advanced disease. However, effective use of UK-licensed and NICE-approved regimens requires the development and full implementation of local policies aimed not only at treatment delivery but also at strategies for predicting, preventing and managing the complications of chemotherapy, notably febrile neutropenia. Such policies, in operation across every cancer network, would save lives and, I believe, reinforce clinicians' confidence in the regimens now at our disposal.

\section{ACKNOWLEDGEMENTS}

My thanks to Succinct Healthcare Communications and Consultancy for editorial support. This supplement is sponsored by an educational grant from sanofi-aventis. The company has checked the factual and medical content, but final editorial control resides with the author and editor.

Conflict of interest

$\mathrm{M}$ Verrill has received consulting fees from Roche.

\section{REFERENCES}

Aapro MS, Cameron DA, Pettengell R, Bohlius J, Crawford J, Ellis M, Kearney N, Lyman GH, Tjan-Heijnen VC, Walewski J, Weber DC, Zielinski C, European Organisation for Research and Treatment of Cancer (EORTC) Granulocyte Colony-Stimulating Factor (G-CSF) Guidelines Working Party (2006) EORTC guidelines for the use of granulocyte-colony stimulating factor to reduce the incidence of chemotherapy-induced febrile neutropenia in adult patients with lymphomas and solid tumours. Eur J Cancer 42: 2433-2453

Ali Z, O'Reilly S, Zahoor T, Schofield P, Malik Z (2008) Experience of febrile neutropaenia and secondary G-CSF prophylaxis during FEC-D chemotherapy in Merseyside and Cheshire Cancer Network. National Cancer Research Institute Conference; Abstract B67

Bear HD, Anderson S, Smith RE, Geyer Jr CE, Mamounas EP, Fisher B, Brown AM, Robidoux A, Margolese R, Kahlenberg MS, Paik S, Soran A, Wickerham DL, Wolmark N (2006) Sequential preoperative or postoperative docetaxel added to preoperative doxorubicin plus cyclophosphamide for operable breast cancer: National Surgical Adjuvant Breast and Bowel Project protocol B-27. J Clin Oncol 24: 2019-2027

Bonadonna G, Brusamolino E, Valagussa P, Rossi A, Brugnatelli L, Brambilla C, De Lena M, Tancini G, Bajetta E, Musumeci R, Veronesi
U (1976) Combination chemotherapy as an adjuvant treatment in operable breast cancer. $N$ Engl J Med 294: 405-410

Bonadonna G, Monfardini S, De Lena M, Fossati-Bellani F (1969) Clinical evaluation of adriamycin, a new antitumour antibiotic. $\mathrm{Br} \mathrm{Med} J \mathrm{~J}$ : $503-506$

British National Formulary Number 57 (2009) Available at: http:// www.bnf.org/bnf/bnf/current/104945.htm (accessed March 2009)

Cameron D (2009) Management of chemotherapy-associated febrile neutropenia. Br J Cancer 101 (Suppl 1): S18-S22

Cancer Research UK (2009) CancerStats key facts on breast cancer. Available at: http://info.cancerresearchuk.org/cancerstats/types/breast/ (accessed March 2009)

Citron ML, Berry DA, Cirrincione C, Hudis C, Winer EP, Gradishar WJ Davidson NE, Martino S, Livingston R, Ingle JN, Perez EA, Carpenter J, Hurd D, Holland JF, Smith BL, Sartor CI, Leung EH, Abrams J, Schilsky RL, Muss HB, Norton L (2003) Randomized trial of dose-dense versus conventionally scheduled and sequential versus concurrent combination chemotherapy as postoperative adjuvant treatment of node-positive primary breast cancer: first report of Intergroup Trial C9741/Cancer and Leukemia Grtoup B Trial 9741. J Clin Oncol 21: 1431-1439 
Coleman R, Thorpe H, Cameron D, Bell R, Dodwell D, Keane M, Gil M, Cousins J, Burkinshaw R (2006) Zoledronic acid is well tolerated and can be safely administered with adjuvant chemotherapy - first safety data from the AZURE trial (BIG01/04). San Antonio Breast Cancer Symposium; Abstract 2080

Cullen M, Baijal S (2009) Prevention of febrile neutropenia: use of prophylactic antibiotics. Br J Cancer 101(Suppl 1): S11-S14

Farber S, Diamond LK, Mercer RD, Sylvester RF, Wolff JA (1948) Temporary remissions in acute leukemia in children produced by folic antagonist, 4-aminopteroylglutamic acid (aminopterin). $N$ Engl J Med 238: $787-793$

Fisher B, Brown AM, Dimitrov NV, Poisson R, Redmond C, Margolese RG, Bowman D, Wolmark N, Wickerham DL, Kardinal CG (1990) Two months of doxorubicin-cyclophosphamide with and without interval reinduction therapy compared with 6 months of cyclophosphamide, methotrexate, and fluorouracil in positive-node breast cancer patients with tamoxifen- nonresponsive tumors: results from the Nation Surgical Adjuvant Breast and Bowel Project B-15. J Clin Oncol 8: 1483-1496

Fisher B, Jeong JH, Anderson S, Bryant J, Fisher ER, Wolmark N (2002) Twenty-five-year follow-up of a randomized trial comparing radical mastectomy, total mastectomy, and total mastectomy followed by irradiation. $N$ Engl J Med 347: 567-575

French Adjuvant Study Group (2001) Benefit of a high-dose epirubicin regimen in adjuvant chemotherapy for node-positive breast cancer patients with poor prognostic factors: 5-year follow-up results of French Adjuvant Study Group 05 randomized trial. J Clin Oncol 19: 602-611

Gilman A (1946) The biological actions and therapeutic applications of the B-chloroethyl amines and sulfides. Science 103: 409-436

Goodman LS, Wintrobe MM, Dameshek W, Goodman MJ, Gilman A, McLennan MT (1984) Nitrogen mustard therapy. Use of methyl-bis (beta-chloroethyl)amine hydrochloride and tris(beta-chloroethyl)amine hydrochloride for Hodgkin's disease, lymphosarcoma, leukemia and certain allied and miscellaneous disorders. J Am Med Assoc 251: $2255-2261$

Halsted WS (1907) The results of radical operations for the cure of carcinoma of the breast. Ann Surg 46: 1-19

Head J, Archer C, Harper-Wynne C, Sinha R, Ring A, Banner R, Sutherland S, Johnston S (2008) Rates of neutropaenic sepsis with the use of adjuvant FEC100-Docetaxel (FEC100-T) chemotherapy in high-risk node-positive patients with early breast cancer; a UK perspective. National Cancer Research Institute Conference; Abstract B64

Heidelberger C, Leibman KC, Harbers E, Bhargava PM (1957) The comparative utilization of uracil-2- $\mathrm{C}^{14}$ by liver, intestinal mucosa, and Flexner-Jobling carcinoma in the rat. Cancer Res 17: 399-404

Henderson C, Berry DA, George D, Cirrincione CT, Goldstein LJ, Martino S, Ingle JN, Cooper MR, Hayes DF, Tkaczuk KH, Fleming G, Holland JF, Duggan DB, Carpenter JT, Frei III E, Schilsky RL, Wood WC, Muss HB, Norton L (2003) Improved outcomes from adding sequential paclitaxel but not from escalating doxorubicin dose in an adjuvant chemotherapy regimen for patients with node-positive primary breast cancer. $J$ Clin Oncol 21: 976-983

Kelly S, Wheatley D (2009) Prevention of febrile neutropenia: use of granulocyte colony-stimulating factors. Br J Cancer 101(Suppl 1): S6-S10

Levine MN, Bramwell VH, Pritchard KI, Norris BD, Shepherd LE, AbuZahra H, Findlay B, Warr D, Bowman D, Myles J, Arnold A, Vandenberg T, MacKenzie R, Robert J, Ottaway J, Burnell M, Williams CK, Tu D (1998) Randomized trial of intensive cyclophosphamide, epirubicin, and fluorouracil chemotherapy compared with cyclophosphamide, methotrexate, and fluorouracil in premenopausal women with node-positive breast cancer. National Cancer Institute of Canada Clinical Trials Group. J Clin Oncol 16: 2651-2658

Mamounas EP, Bryant J, Lembersky B, Fehrenbacher L, Sedlacek SM, Fisher B, Wickerham DL, Yothers G, Soran A, Wolmark N (2005)
Paclitaxel after doxorubicin plus cyclophosphamide as adjuvant chemotherapy for node-positive breast cancer: results from NSABP B-28. J Clin Oncol 23: 3686-3696

Martin M, Pienkowski T, Mackey J, Pawlicki M, Guastalla JP, Weaver C, Tomiak E, Al-Tweigeri T, Chap L, Juhos E, Guevin R, Howell A, Fornander T, Hainsworth J, Coleman R, Vinholes J, Modiano M, Pinter T, Tang SC, Colwell B, Prady C, Provencher L, Walde D, RodriguezLescure A, Hugh J, Loret C, Rupin M, Blitz S, Jacobs P, Murawsky M, Riva A, Vogel C, Breast Cancer International Research Group 001 Investigators (2005) Adjuvant docetaxel for node-positive breast cancer. $N$ Engl J Med 325: 2302-2313

Martin M, Villar A, Sole-Calvo A, Gonzalez R, Massuti B, Lizon J, Camps C, Carrato A, Casado A, Candel MT, Albanell J, Aranda J, Munarriz B, Campbell J, Diaz-Rubio E, GEICAM Group (Spanish Breast Cancer Research Group), Spain (2003) Doxorubicin in combination with fluorouracil and cyclophosphamide (i.v. FAC regimen, day 1,21) versus methotrexate in combination with fluorouracil and cyclophosphamide (i.v. CMF regimen, day 1,21 ) as adjuvant chemotherapy for operable breast cancer: a study by the GEICAM group. Ann Oncol 14: 833-842

National Chemotherapy Advisory Group (2009) Chemotherapy Services in England: Ensuring Quality and Safety. NCAG: London

National Confidential Enquiry into Patient Outcome and Death (2008) For Better, for Worse? NCEPOD: London

National Institute for Health and Clinical Excellence (2009a) Early and Locally Advanced Breast Cancer: Diagnosis and Treatment. NICE: London

National Institute for Health and Clinical Excellence (2009b) Advanced Breast Cancer: Diagnosis and Treatment. NICE: London

Peto R (2007) The worldwide oxford overview: updated (2005 - 2006) metaanalyses of trial results. Plenary Lecture 1. San Antonio Breast Cancer Symposium

Poole CJ, Earl HM, Hiller L, Dunn JA, Bathers S, Grieve RJ, Spooner DA, Agrawal RK, Fernando IN, Brunt AM, O'Reilly SM, Crawford SM, Rea DW, Simmonds P, Mansi JL, Stanley A, Harvey P, McAdam K, Foster L, Leonard RC, Twelves CJ, NEAT Investigators and the SCTBG (2006) Epirubicin and cyclophosphamide, methotrexate, and fluorouracil as adjuvant therapy for early breast cancer. $N$ Engl J Med 355: 1851-1862

Roché H, Fumoleau P, Spielmann M, Canon JL, Delozier T, Serin D, Symann M, Kerbrat P, Soulié P, Eichler F, Viens P, Monnier A, Vindevoghel A, Campone M, Goudier MJ, Bonneterre J, Ferrero JM, Martin AL, Genève J, Asselain B (2006) Sequential adjuvant epirubicinbased and docetaxel chemotherapy for node-positive breast cancer patients: the FNCLCC PACS 01 trial. J Clin Oncol 24: 5664-5671

Sakorafas GH (2008) The origins of radical mastectomy. AORN J 88: $605-608$

Smith E (2006) The Edwin Smith Surgical Papyrus: hieroglyphic transliteration, translation and commentary V1. Breasted JH (ed) Kessinger Publishing: Montana

Smith TJ, Khatcheressian J, Lyman GH, Ozer H, Armitage JO, Balducci L, Bennett CL, Cantor SB, Crawford J, Cross SJ, Demetri G, Desch CE, Pizzo PA, Schiffer CA, Schwartzberg L, Somerfield MR, Somlo G, Wade JC, Wade JL, Winn RJ, Wozniak AJ, Wolff AC (2006) 2006 update of recommendations for the use of white blood cell growth factors: an evidence-based clinical practice guideline. J Clin Oncol 24: 3187-3205

Wani MC, Taylor HL, Wall ME, Coggon P, McPhail AT (1971) Plant antitumor agents. VI. Isolation and structure of taxol, a novel antileukemic and antitumor agent from Taxus brevifolia. J Am Chem Soc 96: $2325-2327$

Winter MC, Thorpe HC, Burkinshaw R, Beevers SJ, Coleman RE (2008) The addition of zoledronic acid to neoadjuvant chemotherapy may influence pathological response - exploratory evidence for direct anti-tumor activity in breast cancer. San Antonio Breast Cancer Symposium; Abstract 5101 